Article

\title{
Spatial Variation of Surface Energy Fluxes Due to Land Use Changes across China
}

\author{
Enjun Ma ${ }^{1, *}$, Xiangzheng Deng ${ }^{2,3}$, Qian Zhang ${ }^{4}$ and Anping Liu ${ }^{1}$
}

1 School of Mathematics and Physics, China University of Geosciences (Wuhan), Wuhan 430074, China; E-Mail: wh.apliu@gmail.com

2 Institute of Geographic Sciences and Natural Resources Research, Chinese Academy of Sciences, Beijing 100101, China; E-Mail: dengxz.ccap@igsnrr.ac.cn

3 Center for Chinese Agricultural Policy, Chinese Academy of Sciences, Beijing 100101, China

4 Department of Urban Planning and Environment, Royal Institute of Technology-KTH, Drottning Kristinas väg 30, SE 10044 Stockholm, Sweden; E-Mail: qian.zhang@abe.kth.se

* Author to whom correspondence should be addressed; E-Mail: maej.simlab@gmail.com; Tel.: +86-10-6488-8385; Fax: +86-10-6485-6533.

Received: 22 January 2014; in revised form: 13 March 2014 / Accepted: 1 April 2014 / Published: 8 April 2014

\begin{abstract}
We estimate the heat flux changes caused by the projected land transformation over the next 40 years across China to improve the understanding of the impacts of land dynamics on regional climate. We use the Weather Research and Forecasting (WRF) model to investigate these impacts in four representative land transformation zones, where reclamation, overgrazing, afforestation, and urbanization dominates the land use and land cover changes in each zone respectively. As indicated by the significant variance of albedo due to different land use and cover changes, different surface properties cause great spatial variance of the surface flux. From the simulation results, latent heat flux increases by 2 and $21 \mathrm{~W} / \mathrm{m}^{2}$ in the reclamation and afforestation regions respectively. On the contrary, overgrazing and urban expansion results in decrease of latent heat flux by 5 and $36 \mathrm{~W} / \mathrm{m}^{2}$ correspondingly. Urban expansion leads to an average increase of $40 \mathrm{~W} / \mathrm{m}^{2}$ of sensible heat flux in the future 40 years, while reclamation, afforestation, as well as overgrazing result in the decrease of sensible heat flux. Results also show that reclamation and overgrazing lead to net radiation decrease by approximately 4 and $7 \mathrm{~W} / \mathrm{m}^{2}$ respectively, however, afforestation and urbanization lead to net radiation increase by 6 and $3 \mathrm{~W} / \mathrm{m}^{2}$ respectively. The simulated impacts of projected HLCCs on surface energy fluxes will inform sustainable land management and climate change mitigation.
\end{abstract}


Keywords: land use and land cover changes; heat flux; WRF; China

\section{Introduction}

Land use/cover change (LUCC) affects climate system at local, regional and global scales through various biogeochemical and biogeophysical processes [1-3]. LUCC would alter the physical properties of land surface, such as albedo, fractional vegetation coverage, moisture content and surface roughness. These physical properties determine the absorption, emission, and exchange of energy at the Earth's surface [1,4], represented by the fluxes of energy, radiation and moisture into atmosphere, etc. [5-9] and consequently affect climate system [10-12]. Furthermore, the interaction between land surface and atmosphere mainly works through the exchanges of momentum, energy and water, among which the exchange of energy plays a key role in affecting climate system. In this context, it is of great importance to investigate the effects of LUCC on surface energy fluxes.

The effects of LUCC on climatic change have raised growing concern and have been widely studied [1,13-15]. There have been many studies that attempted to reveal the impacts of human-induced land cover changes (HLCCs) on the regional climate in China $[3,14,16,17]$. However, most of these studies only focused on the effects of HLCCs on temperature and precipitation [18-21]; little is known about the effects on surface energy fluxes so far, such as latent heat flux and sensible heat flux. Moreover, previous studies on China just concentrated on one typical case study areas, for example, Northeast China, Northwest China, Jiangxi Province and the Pearl River Delta, which are characterized by different types of LUCC. To date, an integrated analysis at the national level in China remained underexplored, which is needed to make comprehensive policies regarding land planning and management.

In order to address this knowledge gap, we estimate the heat flux changes caused by land transformation over the next 40 years across China to improve the understanding of the impacts of land dynamics on regional climate. In this study, we use the Weather Research and Forecasting (WRF) model to investigate these impacts in four representative land transformation zones where reclamation, overgrazing, afforestation, and urbanization dominants the land use and land cover changes separately. The remainder of the paper is structured as follows. First, we describe the study area and introduce the main datasets used in this study (Section 2). Next, we present the methodology in Section 3. We then analyze and discuss the simulation results in detail (Section 4). Finally, we highlight the major findings in Section 5.

\section{Study Area and Data}

\subsection{Selection of the Study Area}

We measured the regional variance of LUCC by Land Use Dynamic Degree [22]. Specifically, we overlap the vector data of land use dynamics from 2000 to 2008 on the $10 \mathrm{~km} \times 10 \mathrm{~km}$ grid data, and then we calculate and summarize the percentages of each changing type of land use within each grid. To present the dominant changing types of land use in the study areas, four zones are selected as the representatives for four types of land transformation: cultivated land reclamation, overgrazing, 
afforestation and urbanization. Land use changes in China have obvious regional differentiation characteristics during 2000 to 2008 (Figure 1). Specifically, the grassland was reclaimed to cultivated land in northeast plain, eastern Inner Mongolia, northwest arid areas as well as part of traditional oasis agricultural region (Zone I).Western Inner Mongolia, loess plateau area were mainly characterized by grassland degradation (Zone II). Land use changes in mountainous Southern China, especially Jiangxi province, were dominated by reforestation or expansion of grasslands due to farmland abandonment (Zone III). In the Huang-Huai-Hai Plain and the southeastern coastal areas (especially the Bohai Economic Rim and the Yangtze River Delta), there is an apparent expansion tendency of residential, industrial, and mining land uses (Zone IV). The four zones are of heterogeneous structure and several types of land use changes occurred in each zone simultaneously. However, we only presented the impacts of dominant type of land use changes on surface heat flux in each zone. In other words, we merely take account of reclamation, overgrazing, afforestation, and urbanization in zones I-IV correspondingly.

Figure 1. Main land use and land cover change in China, 2000-2008.

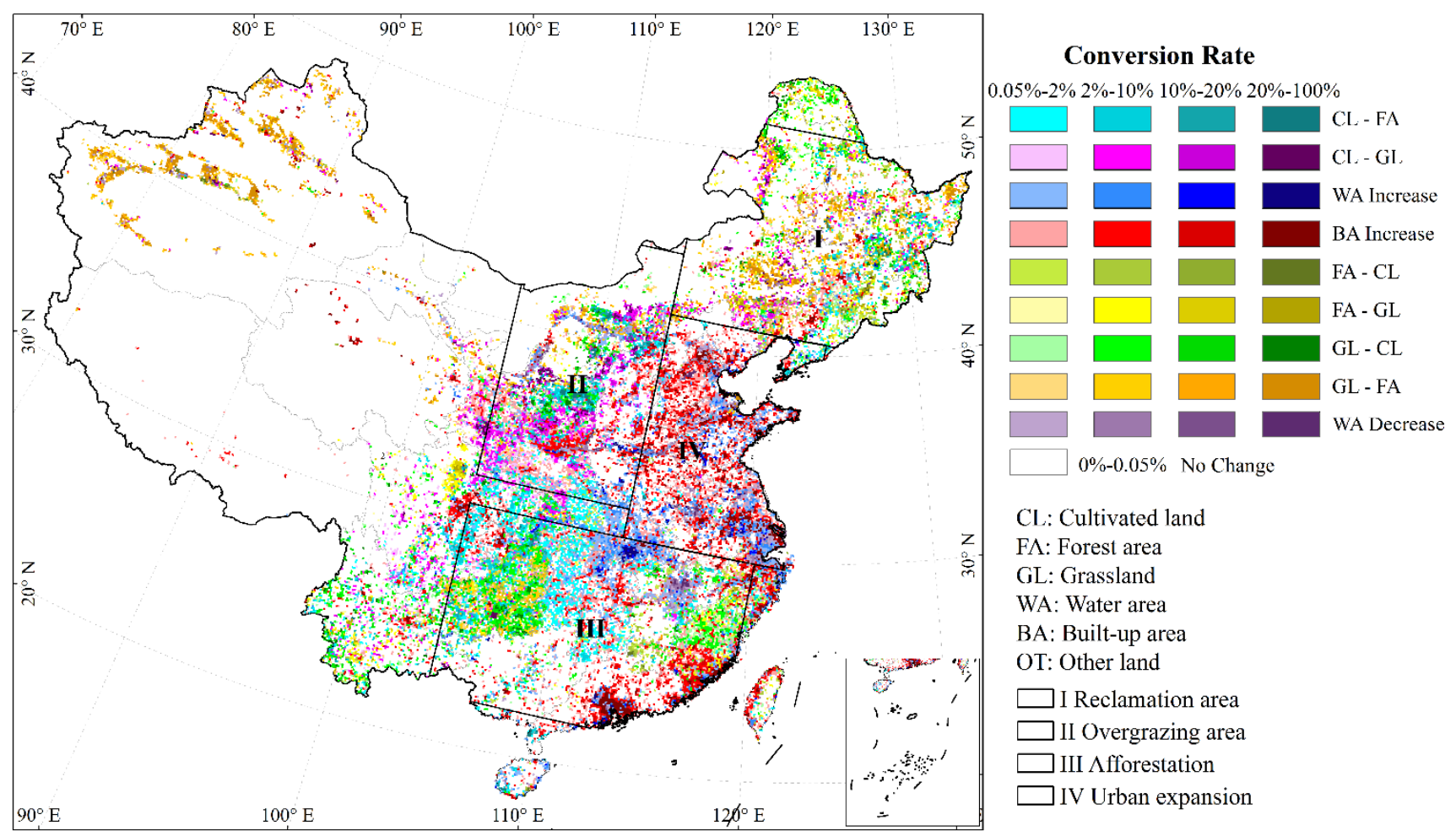

The reason why we selected these four representative types of land use changes is twofold. On the one hand, these four typical types of land use changes happened widely in China. On the other hand, these land transformations have significant climatic impacts according to the previous studies. In detail, the large scale cultivated land reclamation in China started since the last century due to the continual population growth and economic development. Such rapid expansion of cultivated land suggests an intense clearance of natural vegetation, which exerts significant impacts on the climate. Grassland accounts for $40 \%$ of the total land area of China and the grassland degradation and desertification in China have been greatly intensified due to overgrazing, overexploitation of the natural resources, rapid population growth and expansion of road network in the past decades [23]. The serious overgrazing led to grassland degradation, and caused severe grassland productivity degradation and increased the 
frequency of extreme climate events, such as droughts and fierce freeze-up, and consequently led to acute contradiction between the human and nature in this region [24,25]. A number of afforestation projects have been carried out in China, such as "Grain for Green Project" and "One Big Four Small Project", which has made great contribution to the its forestry area. Afforestation is one of the most noticeable human activities and has affected the climate not only as a carbon sink but also by changing the land surface thermal properties [26]. Rapid urbanization dramatically alters the land surface properties, and thus affects the surface energy fluxes, and consequently exerts great influence on the regional climate [27-30]. To sum up, impacts of typical HLCCs on regional climate and environment should be explored in detail, which can shed light on sustainable land management and climate change mitigation [31].

\subsection{Data Source}

The underlying surface data of the four case study areas are presented in this section. The dataset of future land use and land cover from 2010 to 2100 in China was simulated with the Dynamics of Land System (DLS) model [32] and derived from the study by Yuan et al. [33]. The land use/land cover dataset of 2010 and 2050 was classified according to the land use and land cover classification system of the United States Geological Survey (USGS). In this study, the $1 \mathrm{~km} \times 1 \mathrm{~km}$ grid data was integrated into the $10 \mathrm{~km} \times 10 \mathrm{~km}$ grid data by resampling.

In Figure 2, four bars show the dynamic area of the dominant land use and cover changes in these four study areas from 2010 to 2050, and the percentages attached to the bars indicate the proportions of the representative land use types to the total area of this region in 2010 and 2050 correspondingly.

Figure 2. Area and percentage of dominant land use and land cover in each zone.

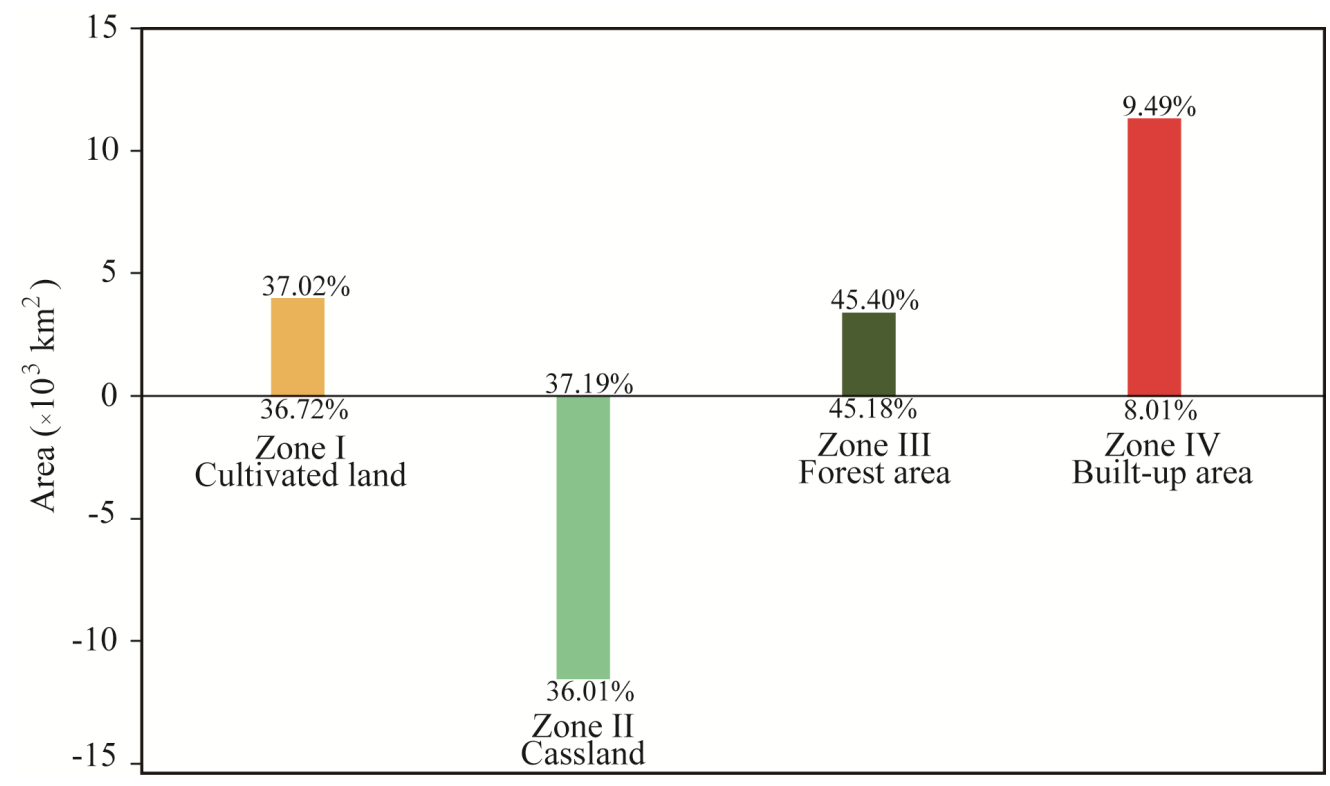

For Zone I, cultivated land in 2010 is approximate $450,000 \mathrm{~km}^{2}$, which accounts for $36.7 \%$ of the total land area of this zone, with an increasing rate of $0.3 \%$ from 2010 to 2050 . In Zone II, the percentage of grassland decreases from the $37 \%$ to $36 \%$. While the forest increases by about $0.22 \%$ in Zone III, and the proportion of urban area soars from $8 \%$ to $9.5 \%$ in Zone IV. 
The dataset of RCP6.0 simulated by the fifth phase of the Coupled Model Intercomparison Project (CMIP5), was used as the atmospheric forcing data for the WRF-ARW model. This dataset includes the data such as air temperature, specific humidity, sea level pressure, eastward wind, northward wind, and geopotential height of years 2010 to 2050 .

\section{Methodology}

\subsection{General Procedure}

The WRF Model is a state-of-the-art atmospheric simulation system based on the Fifth-Generation Penn State/NCAR Mesoscale Model (MM5). The Advanced Research WRF (WRF-ARW) model is applied to simulate the impacts of LUCC on the surface energy balance in this study (Figure 3). The future spatial variation of surface energy fluxes due to land use changes can be simulated based on different underlying surface data, and the impacts of land use changes on the climate can be quantified through the difference of the two simulation results between the baseline test and sensibility test as follows:

$$
E_{i}=P_{i}-B_{i}
$$

where $E$ refers to the effects of future land use change on the surface energy fluxes; $i$ indexes the annual or monthly average surface energy fluxes; and $P$ and $B$ denotes to the simulation results obtained with the WRF-ARW model based on underlying surface in 2010 and 2050 respectively in this study.

Figure 3. General procedure followed in the study.

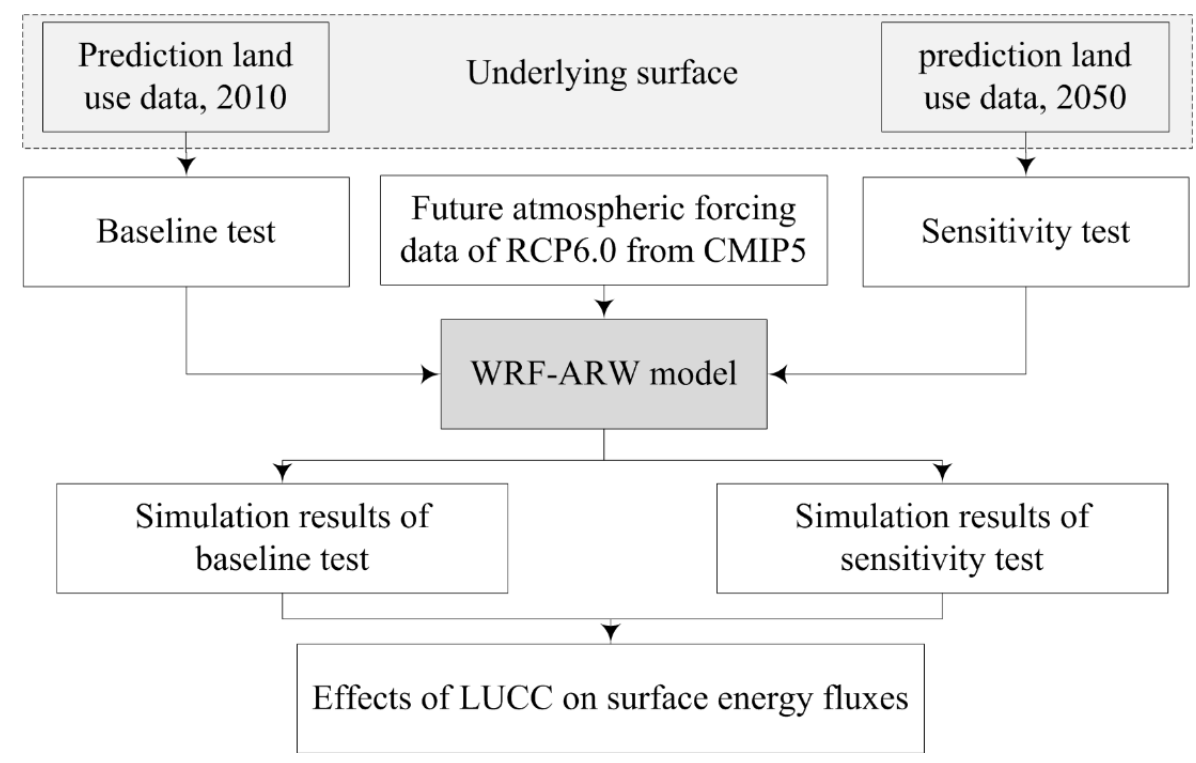

\subsection{Solar Radiation Algorithm}

According to the surface energy budget equation, there is a close relationship between the surface net radiation, land surface albedo, downward shortwave radiation, downward long-wave radiation and land surface emissivity [34]. Energy comes in to the system when sunlight penetrates the top of the 
atmosphere, and it goes out in two ways: reflection by clouds, aerosols, or the surface; and thermal radiation-heat emitted by the surface and the atmosphere, including clouds (Figure 4). The net radiation can be expressed as follows:

$$
\begin{gathered}
R_{n}=(1 \text {-albedo }) S W D O W N+G L W+L W_{\text {out }} \\
L W_{\text {out }}=\text { emissivity } \times \sigma \times T^{4}
\end{gathered}
$$

where $R_{n}$ is the net surface radiation as a function of the surface albedo, incoming short-wave flux $(S W D O W N)$ and long wave flux $(G L W)$ radiation, and outgoing long wave radiation $\left(L W_{\text {out }}\right) ; \sigma$ is the Stefan-Boltzmann constant $\left(\sigma=5.67 \times 10^{-8} \mathrm{~J} \mathrm{~s}^{-1} \mathrm{~m}^{-2} \mathrm{~K}^{-4}\right)$ and $T$ is the land surface temperature. The net radiation is the balance between incoming and outgoing energy at the top of the atmosphere. It is the total energy that is available to influence the climate. This study focuses on how the underlying surface change affects the land surface albedo, downward shortwave radiation, downward long-wave radiation, and land surface emissivity to clarify the key influencing mechanism of the future land use changes on the regional surface radiation across China.

Figure 4. Diagram of the energy balance.

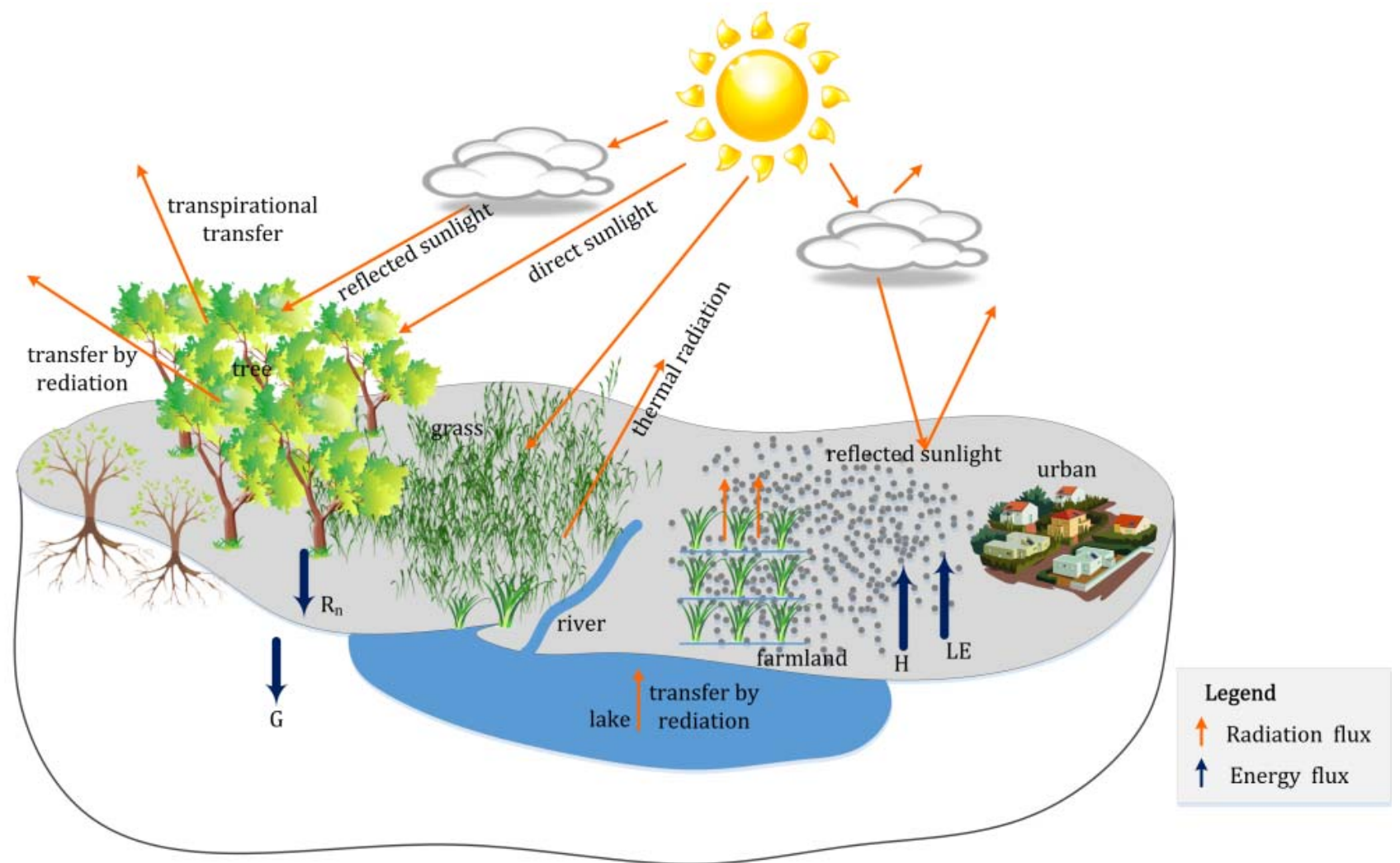

Surface radiation and energy balance are coupled through $R_{n}$. The principal use of this energy is in the phase of changing of water (latent heat flux), changing the temperature of the air (sensible heat flux) and subsurface (ground heat flux) [35]. The surface energy budget can be expressed as follows:

$$
R_{n}=H F X+L E+G F X
$$

where $R_{\mathrm{n}}$ is the net radiation (downwelling minus upwelling solar and infrared radiation); $H F X$ is sensible heat flux; $L E$ is latent heat flux; and $G F X$ is heat flux into the soil. 


\section{Results and Discussion}

\subsection{Spatial Variation of Flux Changes}

During 2010-2050, there are various changes for heat flux among these four representative zones. Figure 5 illustrates the spatial changes of latent heat flux, sensible heat flux and surface net radiation (red represents increase and blue represents decrease). Over all three maps, in the overgrazing area (Zone II), each type of heat flux shows a downward trend while in other three zones, they present upward trends. As expected, changes in surface albedo caused by urban expansion may actually be greater than that caused by cultivated land reclamation, overgrazing and afforestation. The change of energy balance is mainly about decrease of net shortwave radiation and surface sensible heat flux due to increase of surface albedo. As a consequence of widespread afforestation, plant transpiration and surface evapotranspiration will increase and further latent heat flux will increase correspondingly.

It is found that latent heat flux increases about $2 \mathrm{~W} / \mathrm{m}^{2}$ in the Northeast China (Zone I) due to conversion from other land to cultivated land, while in the overgrazing area it mostly decreases by about $5 \mathrm{~W} / \mathrm{m}^{2}$ (Zone II) (Figure 5). In the afforestation area (Zone III), the Southeast China, the increase in latent heat flux will be mostly less than about $21 \mathrm{~W} / \mathrm{m}^{2}$. Meanwhile, latent heat flux decreases by mostly less than about $36 \mathrm{~W} / \mathrm{m}^{2}$ in the surrounding urban expansion area (Zone IV) due to conversion from other land to built-up area. During 2010-2050, sensible heat flux will decrease by approximate 4,2 and $13 \mathrm{~W} / \mathrm{m}^{2}$ in the reclamation area (Zone I), the overgrazing area (Zone II) and afforestation area (Zone III). However, in urban expansion area (Zone IV), sensible heat flux will increase by about $40 \mathrm{~W} / \mathrm{m}^{2}$ and the increase of albedo is associated with sensible heat flux increasing. For Zone I and II, the net radiation will decrease by 4 and $7 \mathrm{~W} / \mathrm{m}^{2}$ respectively. On the contrast, in Zone III and IV, it will increase by 6 and $3 \mathrm{~W} / \mathrm{m}^{2}$ respectively during 2010-2050.

Figure 5. Changes in latent heat flux (a), sensible heat flux (b) and surface net radiation (c) in the four case zones during 2010-2050 (Unit: W/m²).

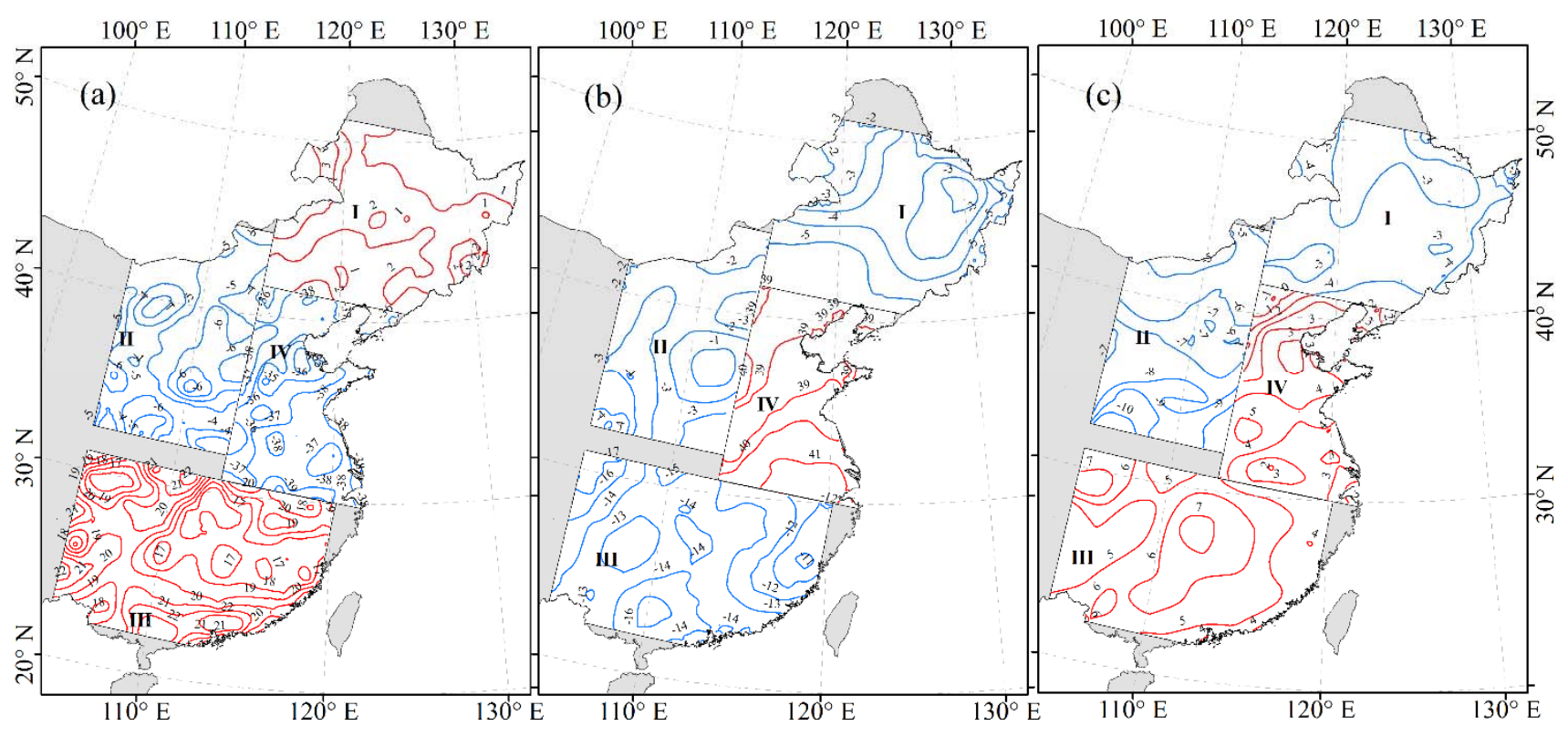




\subsection{Annual Average Heat Flux}

Since each case zone has different types of land use/cover changes, we simulate the changes of heat flux under different types of LUCC in the four case zones. We compare and analyze the differences of heat flux simulations in specified grids with and without changes of land use types. Specifically, in the cultivated land reclamation area, we figure out the grids with the conversions from grassland and forest area to cultivated land, and in the overgrazing area, the specified grids are mainly with the changes to cultivated land, forest area and built-up area at the expense of grassland. In afforestation area, we focus on the land transformation to forest area (such as from cultivated land, grassland and built-up area), while in the urbanization area, the statistics are mainly about the area with the cultivated land, grassland and forest converted to built-up area. Figure 6 shows the effect of LUCC on the heat flux from 2010 to 2050, including latent heat flux and sensible heat flux and net radiation.

Figure 6. Annual average changes of latent heat flux $(L H)$, sensible heat flux $(H)$ and net radiation $(R n)$ in the grids with LUCC from 2010 to 2050. I: reclamation; II: overgrazing; III: afforestation; IV: urban expansion (Unit: $\mathrm{W} / \mathrm{m}^{2}$ ).
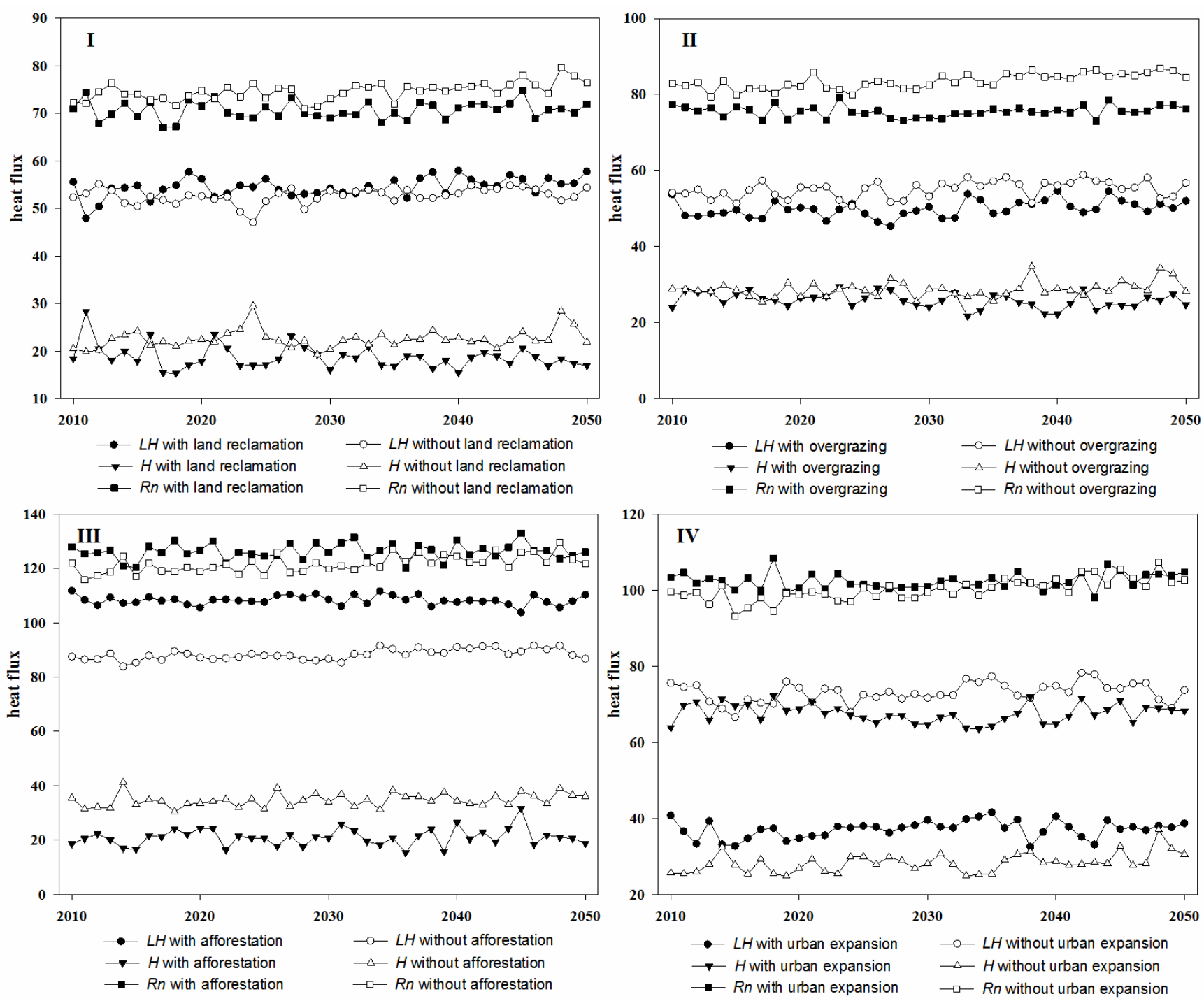
From Figure 6, we find that the net radiation is the highest heat flux while the sensible one is the lowest. In Zone IV, the urban expansion area, latent heat flux with urban expansion and sensible heat without urbanization stay at the bottom. In the former two areas, the differences between the two types simulation are less than $10 \mathrm{~W} / \mathrm{m}^{2}$ for latent heat flux, sensible heat flux and even net radiation. Different from latent heat flux in Zone I, with the situation of land reclamation, the net radiation and sensible heat flux will both be lower than that without it. On the contrary, for the Zone III, latent heat flux has less discrepancy, which is less than $10 \mathrm{~W} / \mathrm{m}^{2}$, but difference of sensible heat flux between the area with and without afforestation is more than $30 \mathrm{~W} / \mathrm{m}^{2}$, and as for the net radiation, the difference is about $20 \mathrm{~W} / \mathrm{m}^{2}$. Under the urban expansion, sensible heat flux increases by about $40 \mathrm{~W} / \mathrm{m}^{2}$ while latent heat flux decreases by about $40 \mathrm{~W} / \mathrm{m}^{2}$.

\subsection{Monthly Average Heat Flux}

In order to figure out the monthly changes between 2010 and 2050, we count and analyze the three kinds of heat flux in the four case zones on a monthly basis (Table 1).

Table 1. Monthly average changes of latent heat flux $(L H)$, sensible heat flux $(H)$ and net radiation $\left(R_{n}\right)$ in the grids with LUCC from 2010 to 2050 (Unit: $\mathrm{W} / \mathrm{m}^{2}$ ).

\begin{tabular}{|c|c|c|c|c|c|c|c|c|c|c|c|c|}
\hline \multirow{2}{*}{ Month } & \multicolumn{3}{|c|}{ Zone I } & \multicolumn{3}{|c|}{ Zone II } & \multicolumn{3}{|c|}{ Zone III } & \multicolumn{3}{|c|}{ Zone IV } \\
\hline & $L H$ & $\boldsymbol{H}$ & $\boldsymbol{R}_{n}$ & $L H$ & $\boldsymbol{H}$ & $\boldsymbol{R}_{n}$ & $L H$ & $\boldsymbol{H}$ & $\boldsymbol{R}_{n}$ & $L H$ & $\boldsymbol{H}$ & $\boldsymbol{R}_{n}$ \\
\hline Jan. & 1.96 & -3.28 & -3.36 & -4.37 & -2.91 & -7.28 & 22.12 & -14.27 & 6.70 & -34.75 & 39.72 & 3.09 \\
\hline Feb. & 2.29 & -3.88 & -3.61 & -4.84 & -2.71 & -8.03 & 20.54 & -17.47 & 2.00 & -35.75 & 38.76 & 1.13 \\
\hline Mar. & 1.96 & -4.12 & -3.80 & -4.93 & -3.73 & -9.09 & 19.97 & -13.36 & 3.44 & -35.74 & 39.02 & 0.66 \\
\hline Apr. & 1.24 & -2.93 & -4.20 & -5.72 & -2.99 & -8.00 & 19.21 & -15.49 & 1.73 & -36.14 & 40.91 & 3.78 \\
\hline May & 1.97 & -4.12 & -4.04 & -4.38 & -0.32 & -4.93 & 20.99 & -11.97 & 7.38 & -33.28 & 41.05 & 5.39 \\
\hline Jun. & 3.17 & -3.49 & -2.34 & -6.11 & -1.32 & -8.02 & 19.39 & -11.92 & 5.86 & -39.01 & 39.57 & -1.34 \\
\hline Jul. & 2.09 & -2.20 & -2.61 & -6.35 & -2.32 & -8.68 & 19.50 & -12.40 & 5.47 & -36.99 & 38.27 & 0.08 \\
\hline Aug. & 0.50 & -3.79 & -5.78 & -4.18 & -5.36 & -10.34 & 20.43 & -10.25 & 8.51 & -34.65 & 39.55 & 3.17 \\
\hline Sep. & 0.65 & -3.85 & -4.65 & -5.52 & -2.91 & -7.75 & 16.60 & -11.79 & 3.35 & -39.56 & 38.90 & -2.68 \\
\hline Oct. & 2.03 & -5.36 & -4.36 & -5.30 & -2.15 & -7.11 & 19.67 & -12.76 & 4.20 & -36.62 & 39.65 & 1.36 \\
\hline Nov. & 2.17 & -4.35 & -4.67 & -4.86 & -3.20 & -7.87 & 20.24 & -16.50 & 3.33 & -35.09 & 38.32 & 1.04 \\
\hline Dec. & 2.14 & -4.08 & -4.67 & -5.00 & -3.02 & -7.27 & 21.93 & -15.20 & 4.30 & -35.57 & 38.59 & 2.19 \\
\hline Average & 1.85 & -3.79 & -4.01 & -5.13 & -2.75 & -7.86 & 20.05 & -13.62 & 4.69 & -36.10 & 39.36 & 1.49 \\
\hline
\end{tabular}

In the cultivated land reclamation area and overgrazing area, the changes are small with less than $10 \mathrm{~W} / \mathrm{m}^{2}$. Latent heat flux in Zone I will increase by about $1.8 \mathrm{~W} / \mathrm{m}^{2}$ on average and in June it will increase by $3.2 \mathrm{~W} / \mathrm{m}^{2}$, which is maximum through the whole year. However, sensible heat flux and net radiation will decrease by 3.8 and $4.0 \mathrm{~W} / \mathrm{m}^{2}$ on average, respectively, and the extreme maximum values will appear in August and October with the minimum ones appearing in June and July, respectively. In the Zone II, both types of heat flux will decrease and the smallest change is the change in sensible heat flux. Because of vegetation changes in Zone III and IV, changes in the heat flux present distinctly. Since the forest area increases, latent heat flux and net radiation increase by about 20 and $4.7 \mathrm{~W} / \mathrm{m}^{2}$ respectively, while sensible one will reduce by about $13.6 \mathrm{~W} / \mathrm{m}^{2}$. In contrast, in the Zone IV due to the green reducing, latent heat flux will decrease by $36 \mathrm{~W} / \mathrm{m}^{2}$ with the maximum 
decrease appearing in September and minimum appearing in May while sensible one increase by $39 \mathrm{~W} / \mathrm{m}^{2}$, with minimum and maximum increase of 38 and $41 \mathrm{~W} / \mathrm{m}^{2}$ appearing in July and May respectively), and the net radiation only changes no more than $1.5 \mathrm{~W} / \mathrm{m}^{2}$ during this period.

\section{Conclusions}

In this study, we investigate the effects of HLCCs on regional climate in typical reclamation, overgrazing, afforestation, and urbanization regions in China with the aid of WRF model. Simulation results show that future HLCCs patterns have significant impacts on the surface energy fluxes. From the simulation results, there is significant variance of albedo under different HLCCs, which suggests that albedo of different underlying surfaces results in spatial variance of the radiation flux. Results show that latent heat flux increase by 2 and $21 \mathrm{~W} / \mathrm{m}^{2}$ in the case of cultivated land reclamation and afforestation respectively. On the contrary, overgrazing and urban expansion leads to latent heat flux decrease by 5 and $36 \mathrm{~W} / \mathrm{m}^{2}$ correspondingly. Simulation results also indicate that urban expansion has significant effect on sensible heat flux, and it leads sensible heat flux to have an average increase of $40 \mathrm{~W} / \mathrm{m}^{2}$ during 2010-2050. Reclamation, afforestation and overgrazing have opposite trends, i.e., decrease sensible heat flux. In addition, net radiation would decrease by approximate 4 and $7 \mathrm{~W} / \mathrm{m}^{2}$ in reclamation and overgrazing dominated region respectively; and increase by 6 and $3 \mathrm{~W} / \mathrm{m}^{2}$ in afforestation and urbanization regions separately.

This study also reveals the seasonal pattern of the impacts of HLCCs on surface heat flux. The considerable changes of latent and sensible heat flux and net radiation appear in winter and spring, especially in the afforestation and urbanization areas. Furthermore, different HLCCs have various effects on monthly variation of latent and sensible heat flux and net radiation. The change tendency of sensible heat flux is consistent with net radiation under various underlying surface types. Urban expansion, afforestation, cultivated land reclamation and overgrazing have different impacts on latent heat flux and the effect of urban expansion is by far the most significant of all. The simulated impacts of projected HLCCs on surface energy fluxes in a relatively long run will shed light on screening climate change mitigation strategies through regulating land use activities.

\section{Acknowledgments}

This research was supported by the National Basic Research Program of China (973 Program) (No. 2010CB950900) and the National Major Scientific Research Program: The Decision Support System for the Integrated Water Resource Management in Heihe River Basin (HRB) (Grant No.91325302).

\section{Author Contributions}

Enjun Ma, Xiangzheng Deng and Qian Zhang designed research; Enjun Ma, Xiangzheng Deng, Qian Zhang, and Anping Liu performed research; Enjun Ma, Xiangzheng Deng, Qian Zhang, and Anping Liu analyzed data; and Enjun Ma, Xiangzheng Deng, Qian Zhang, and Anping Liu wrote the paper. 


\section{Conflicts of Interest}

The authors declare no conflict of interest.

\section{References}

1. Foley, J.A.; Defries, R.; Asner, G.P.; Barford, C.; Bonan, G.; Carpenter, S.R.; Chapin, F.S.; Coe, M.T.; Daily, G.C.; Gibbs, H.K.; et al. Global consequences of land use. Science 2005, 309, 570-574.

2. Arora, V.K.; Montenegro, A. Small temperature benefits provided by realistic afforestation efforts. Nat. Geosci. 2011, 4, 514-518.

3. Deng, X.; Huang, J.; Lin, Y.; Shi, Q. Interactions between climate, socioeconomics, and land dynamics in Qinghai province, China: A LUCD model-based numerical experiment. Adv. Meteorol. 2013, 2013, 297926:1-297926:9.

4. Gates, L.D.; Liess, S. Impacts of deforestation and afforestation in the mediterranean region as simulated by the MPI atmospheric GCM. Glob. Planet. Chang. 2001, 30, 309-328.

5. Zhang, X.; Wang, W.; Fang, X.; Ye, Y.; Zheng, J. Agriculture development-induced surface albedo changes and climatic implications across northeastern China. Chin. Geogr. Sci. 2012, 22, 264-277.

6. Mahmood, R.; Quintanar, A.I.; Conner, G.; Leeper, R.; Dobler, S.; Pielke, R.A.; Beltran-Przekurat, A.; Hubbard, K.G.; Niyogi, D.; Bonan, G.; et al. Impacts of land use/land cover change on climate and future research priorities. Bull. Am. Meteorol. Soc. 2010, 91, $37-46$.

7. Pielke, R.A.; Marland, G.; Betts, R.A.; Chase, T.N.; Eastman, J.L.; Niles, J.O.; Niyogi, D.D.S.; Running, S.W. The influence of land-use change and landscape dynamics on the climate system: Relevance to climate-change policy beyond the radiative effect of greenhouse gases. Philos. Trans. A. Math. Phys. Eng. Sci. 2002, 360, 1705-1719.

8. $\mathrm{Fu}, \mathrm{C}$. Potential impacts of human-induced land cover change on East Asia monsoon. Glob. Planet. Chang. 2003, 37, 219-229.

9. Kant, Y.; Badarinath, K.V.S. Regional scale evapotranspiration estimation using satellite derived albedo and surface temperature. J. Indian Soc. Remote Sens. 1998, 26, 129-134.

10. Betts, R.A. Offset of the potential carbon sink from boreal forestation by decreases in surface albedo. Nature 2000, 408, 187-190.

11. Chase, T.N.; Knaff, J.A.; Pielke Sr, R.A.; Kalnay, E. Changes in global monsoon circulations since 1950. Nat. Hazards 2003, 29, 229-254.

12. Douglas, E.M.; Beltrán-Przekurat, A.; Niyogi, D.; Pielke, R.A.; Vörösmarty, C.J. The impact of agricultural intensification and irrigation on land-atmosphere interactions and Indian monsoon precipitation-A mesoscale modeling perspective. Glob. Planet. Chang. 2009, 67, 117-128.

13. Betts, R. Biogeophysical impacts of land use on present-day climate: Near-surface temperature change and radiative forcing. Atmos. Sci. Lett. 2001, 2, 39-51.

14. Deng, X.; Zhao, C.; Yan, H. Systematic modeling of impacts of land use and land cover changes on regional climate: A review. Adv. Meteorol. 2013, 2013, 317678:1-317678:11. 
15. Silalertruksa, T.; Gheewala, S.H. Food, fuel, and climate change. J. Ind. Ecol. 2012, 16, 541-551.

16. Watson, R.T. Land Use, Land-Use Change, and Forestry: A Special Report of the Intergovernmental Panel on Climate Change; Cambridge University Press: Cambridge, UK, 2000.

17. Wessels, K.J.; Prince, S.D.; Malherbe, J.; Small, J.; Frost, P.E.; VanZyl, D. Can human-induced land degradation be distinguished from the effects of rainfall variability? A case study in South Africa. J. Arid Environ. 2007, 68, 271-297.

18. Qu, R.; Cui, X.; Yan, H.; Ma, E.; Zhan, J. Impacts of land cover change on the near-surface temperature in the North China Plain. Adv. Meteorol. 2013, 2013, 409302:1-409302:12.

19. Yu, R.; Wang, X.; Yan, Z.; Yan, H.; Jiang, Q. Regional climate effects of conversion from grassland to forestland in Southeastern China. Adv. Meteorol. 2013, 2013, 630953:1-630953:9.

20. Li, Z.; Deng, X.; Shi, Q.; Ke, X.; Liu, Y. Modeling the impacts of boreal deforestation on the near-surface temperature in European Russia. Adv. Meteorol. 2013, 2013, 486962:1-486962:9.

21. Lin, Y.; Liu, A.; Ma, E.; Li, X.; Shi, Q. Impacts of future urban expansion on regional climate in the Northeast Megalopolis, USA. Adv. Meteorol. 2013, 2013, 362925:1-362925:10.

22. Liu, J.; Zhang, Z.; Xu, X.; Kuang, W.; Zhou, W.; Zhang, S.; Li, R.; Yan, C.; Yu, D.; Wu, S. Spatial patterns and driving forces of land use change in China during the early 21 st century. J. Geogr. Sci. 2010, 20, 483-494.

23. Xu, G.C.; Kang, M.Y.; Jiang, Y. Adaptation to the policy-oriented livelihood change in Xilingol grassland, Northern China. Procedia Environ. Sci. 2012, 13, 1668-1683.

24. Deng, X.; Huang, J.; Huang, Q.; Rozelle, S.; Gibson, J. Do roads lead to grassland degradation or restoration? A case study in Inner Mongolia, China. Environ. Dev. Econ. 2011, 16, 751-773.

25. Li, Y. Numerical simulation of the effects of grassland degradation on the surface climate in overgrazing area of Northwest China. Adv. Meteorol. 2013, 2013, 270192:1-270192:9.

26. Metz, B. Climate Change 2007-Mitigation of Climate Change: Working Group III Contribution to the Fourth Assessment Report of the IPCC; Cambridge University Press: Cambridge, UK, 2007; Volume 4.

27. Seto, K.C.; Shepherd, J.M. Global urban land-use trends and climate impacts. Curr. Opin. Environ. Sustain. 2009, 1, 89-95.

28. Lam, C.-Y. On climate changes brought about by urban living. Des. High Density Cities Soc. Environ. Sustain. 2010, 5, 55-61.

29. Chen, J.; Li, Q.; Niu, J.; Sun, L. Regional climate change and local urbanization effects on weather variables in Southeast China. Stoch. Environ. Res. Risk Assess. 2011, 25, 555-565.

30. Seto, K.C.; Satterthwaite, D. Interactions between urbanization and global environmental change. Curr. Opin. Environ. Sustain. 2010, 2, 127-128.

31. Bonan, G.B. Forests and climate change: Forcings, feedbacks, and the climate benefits of forests. Science 2008, 320, 1444-1449.

32. Deng, X.; Jiang, Q.; Zhan, J.; He, S.; Lin, Y. Simulation on the dynamics of forest area changes in Northeast China. J. Geogr. Sci. 2010, 20, 495-509.

33. Yuan, Y.; Zhao, T.; Wang, W.; Chen, S.; Wu, F. Projection of the Spatially Explicit Land Use/Cover Changes in China, 2010-2100. Adv. Meteorol. 2013, 2013, 908307:1-908307:9. 
34. Tao, Z.; Santanello, J.A.; Chin, M.; Zhou, S.; Tan, Q.; Kemp, E.M.; Peters-Lidard, C.D. Effect of land cover on atmospheric processes and air quality over the continental United States-A NASA Unified WRF (NU-WRF) model study. Atmos. Chem. Phys. 2013, 13, 6207-6226.

35. Ritter, M.E. The Physical Environment: An Introduction to Physical Geography http://www.earthonlinemedia.com/ebooks/tpe_3e/contents.html (accessed on 2 November 2013).

(C) 2014 by the authors; licensee MDPI, Basel, Switzerland. This article is an open access article distributed under the terms and conditions of the Creative Commons Attribution license (http://creativecommons.org/licenses/by/3.0/). 